\title{
GM-CSF and IL-2 as adjuvant enhance the immune effect of protein vaccine against foot-and-mouth disease
}

\author{
Can Zhang ${ }^{1,3}$, Bin Wang ${ }^{2}$, Ming Wang ${ }^{1 *}$
}

\begin{abstract}
Background: Cytokines as molecular adjuvant play a critical role in differentiation of effector T cell subsets and in determination of the magnitude of the response after vaccination. In this study, we investigated the effects of GM-CSF and IL-2 as adjuvant on the immune responses of VP1 recombinant protein as a model antigen for foot and mouth disease.

Results: Six expression plasmids were constructed and expressed in E. coli BL21. In guinea pigs, the immunological and molecular effects of the fusion proteins were determined by ELISA, LPA, DTH and semi-quantitative Reverse Transcriptase PCR (RT-PCR). The data revealed that IL-2 and GM-CSF as adjuvant of VP1 could stimulate both humoral and cell-mediated immune response. Interestingly, IL-2 and GM-CSF, either as a co-expressed protein or as a mixture of two single proteins, showed much better adjuvant effects than that of single one.
\end{abstract}

Conclusions: IL-2 and GM-CSF could be used as a potential adjuvant for VP1 and had synergistic effect when co-expressed or mixed with VP1.

\section{Background}

In recent years, there has been significant progress in the development of candidate vaccines against foot and mouth disease virus (FMDV), in the forms of both whole virus and recombinant proteins. Practical application of these vaccines, however, has often been limited by the lack of suitable adjuvant capable of stimulating an appropriate immune response in the absence of adverse reactions.

Many compounds with adjuvant activity have been identified, but none has been emerged as being universally superior [1,2]. Although adjuvant such as alum adjuvant has been widely used with vaccines for many years [3], alum does not effectively augment immune response necessary for a number of new subunit protein or peptide based vaccines [4]. There is a strong need for alternative adjuvants that must not only enhance the immune response but also drive it to achieve the appropriate type of protective immunity in each situation.

\footnotetext{
* Correspondence: vetdean@cau.edu.cn

${ }^{1}$ College of Veterinary Medicine, China Agricultural University, Beijing 100193, China

Full list of author information is available at the end of the article
}

It is now evident that molecular adjuvant, especially cytokines [5-7], could enhance and modulate the immune responses induced by subunit vaccine. In many studies cytokines were used to reinforce the ability of the subunit vaccine to induce antigen-specific cellular immune response against FMDV [8-11].

IL-2 is one of the most widely used adjuvants for vaccination to stimulate the proliferation and activation of various immune effector cells such as T cells, NK cells, B cells, and macrophages [12,13]. Granulocyte monocyte colony stimulating factor (GM-CSF) is known to stimulate macrophage differentiation and proliferation, and to activate antigen presenting cells [14]. IL-2 and GM-CSF has been used as an effective adjuvant for DNA or peptide based vaccines [15-17].

In this immunization study, we selected IL-2 and GM-CSF as adjuvant for the VP1 subunit vaccine, with an ultimate goal to verify whether these cytokines have the ability to stimulate humoral immune response and cellular immunity for FMDV.

\section{Biomed Central}

(c) 2011 Zhang et al; licensee BioMed Central Ltd. This is an Open Access article distributed under the terms of the Creative Commons Attribution License (http://creativecommons.org/licenses/by/2.0), which permits unrestricted use, distribution, and reproduction in any medium, provided the original work is properly cited. 


\section{Results}

Construction of expression plasmids of BolL-2, BoGM-CSF and VP1

Bovine IL-2 (BoIL-2), Bovine GM-CSF (BoGM-CSF) and VP1 gene were amplified and cloned into pGEX-6P-1 vector by using the restriction enzymes as described before. Each construct was characterized by restriction mapping with one vector band and specific target bands at $405 \mathrm{bp}, 450 \mathrm{bp}, 378 \mathrm{bp}$ and $669 \mathrm{bp}$, respectively, followed by DNA sequencing. The results showed that the plasmids of BoIL-2, BoGM-CSF and VP1 were correctly constructed with sequence integrity and right orientation.

\section{Construction of co-expression plasmids of BolL-2, BoGM-CSF and VP1}

BoIL-2, BoGM-CSF and VP1 gene fragments were amplified and cloned into pGEX-6P-1 vector by using the restriction enzymes as described before. To construct fused products of BoIL-2/BoGM-CSF/VP1, BoIL-2/VP1, BoGM-CSF/VP1, These constructs were characterized by double digestion with the corresponding restriction enzymes and yielded fragments including one vector band and specific target bands, of which 669 bp was expected for the VP1, 405 bp for the BoIL-2, 378 bp for the BoGM-CSF, 1089 bp for the BoIL-2/VP1, $1062 \mathrm{bp}$ for the BoGM-CSF/VP1 and $1482 \mathrm{bp}$ for the BoIL-2/BoGM-CSF/VP1, respectively. It was further confirmed by PCR with respective primers.

\section{Characterization of the expressed proteins by SDS-PAGE and Western blot analysis}

To analyze the expressed products, $20 \mu \mathrm{l}$ samples from the supernatant and precipitation fractions of each culture were analyzed by SDS-PAGE. The result showed that all products were GST fusion proteins and expressed in inclusion body. $40 \mathrm{KDa}, 51 \mathrm{KDa}, 41 \mathrm{KDa}$, $65 \mathrm{KDa}, 66 \mathrm{KDa}$, and $81 \mathrm{KDa}$ were observed and represented the sizes of BoGM-CSF, VP1, BoIL-2, BoGM-CSF/VP1, BoIL-2/VP1, BoIL-2/BoGM-CSF/VP1, respectively (Figure 1 ). The yield of expression for each product is approximately $37 \%$ of the total cellular proteins. These constructs were further confirmed by Western-blots (Figure 2).

\section{Dynamics of serum IgG of FMDV in the inoculated guinea pigs}

To evaluate the levels of total IgG against FMDV, the sera obtained from immunized guinea pigs two week after each injection were diluted 1:100 to perform ELISA as shown in Figure 3. The IgG level of serum samples of all groups was increased along with the immunization time. Compared with the control group,

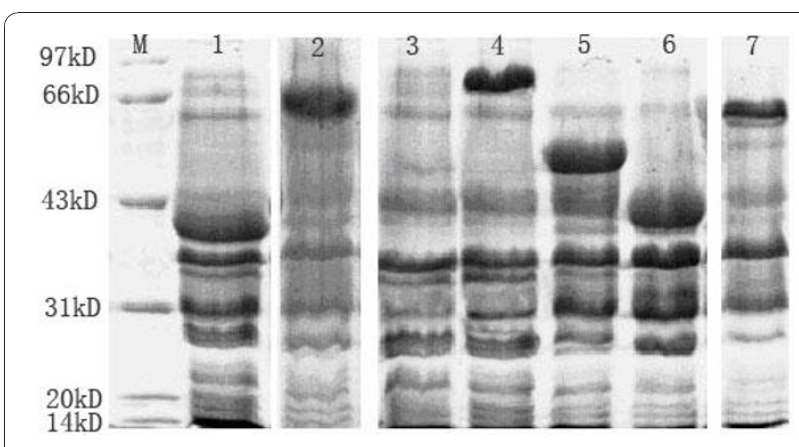

Figure 1 SDS-PAGE analysis of recombinant protein expressed in BL21. $20 \mu$ l precipitation was sampled from each cultural and analyzed on 15\% SDS-PAGE. The results showed that the expressed products were respectively expressed in precipitation with specific target bands of $40 \mathrm{KDa}, 66 \mathrm{KDa}, 81 \mathrm{KDa}, 51 \mathrm{KDa}, 41 \mathrm{KDa}$ and 65 $\mathrm{KDa}$, which were well corresponded to the sizes of BoGM-CSF, BolL-2NP1, BolL-2/GM-CSFNP, VP1, BolL-2, BoGM-CSFNP1. (Lane M: Low molecular weight standard protein marker, Lane 1: BoGM-CSF, Lane 2:BolL-2NP1, Lane 3: control, Lane 4: BolL-2/GM-CSFNP1, Lane 5: VP1, Lane 6: BolL-2, Lane 7: BoGM-CSFNP1).

sera were detected positive in groups of BoIL-2/BoGMCSF/VP1, BoIL-2+BoGM-CSF/VP1 and negative in others after the first immunization. After the second and third immunizations, IgG levels were significant higher and increased fast after the third injection in all immunized groups.

Among the groups, IgG levels of BoIL-2/BoGM-CSF/ VP1 and BoIL-2/VP1+BoGM-CSF/VP1 groups were statistically significantly higher than those of other groups $(\mathrm{P}<0.05)$. The second high level of IgG was observed

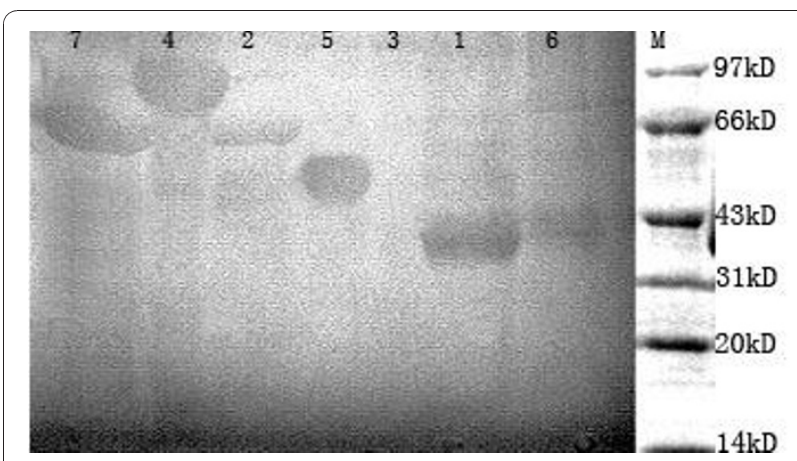

Figure 2 Western blot analysis of recombinant protein expressed in BL21. Recombinant proteins were purified and analyzed by Western blot. In Western blot analysis, guinea pig antiBolL-2 sera, guinea pig anti-BoGM-CSF sera and bovine FMDV positive sera were respectively used as the primary antibodies, and the expressions of recombinant proteins were all detected with one specific target band, respectively. (Lane M: Low molecular weight standard protein marker, Lane 1: BoGM-CSF, Lane 2:BolL-2NP1, Lane 3: control, Lane 4: BolL-2/GM-CSFNP1, Lane 5: VP1, Lane 6: BolL-2, Lane 7: BoGM-CSFNP1). 


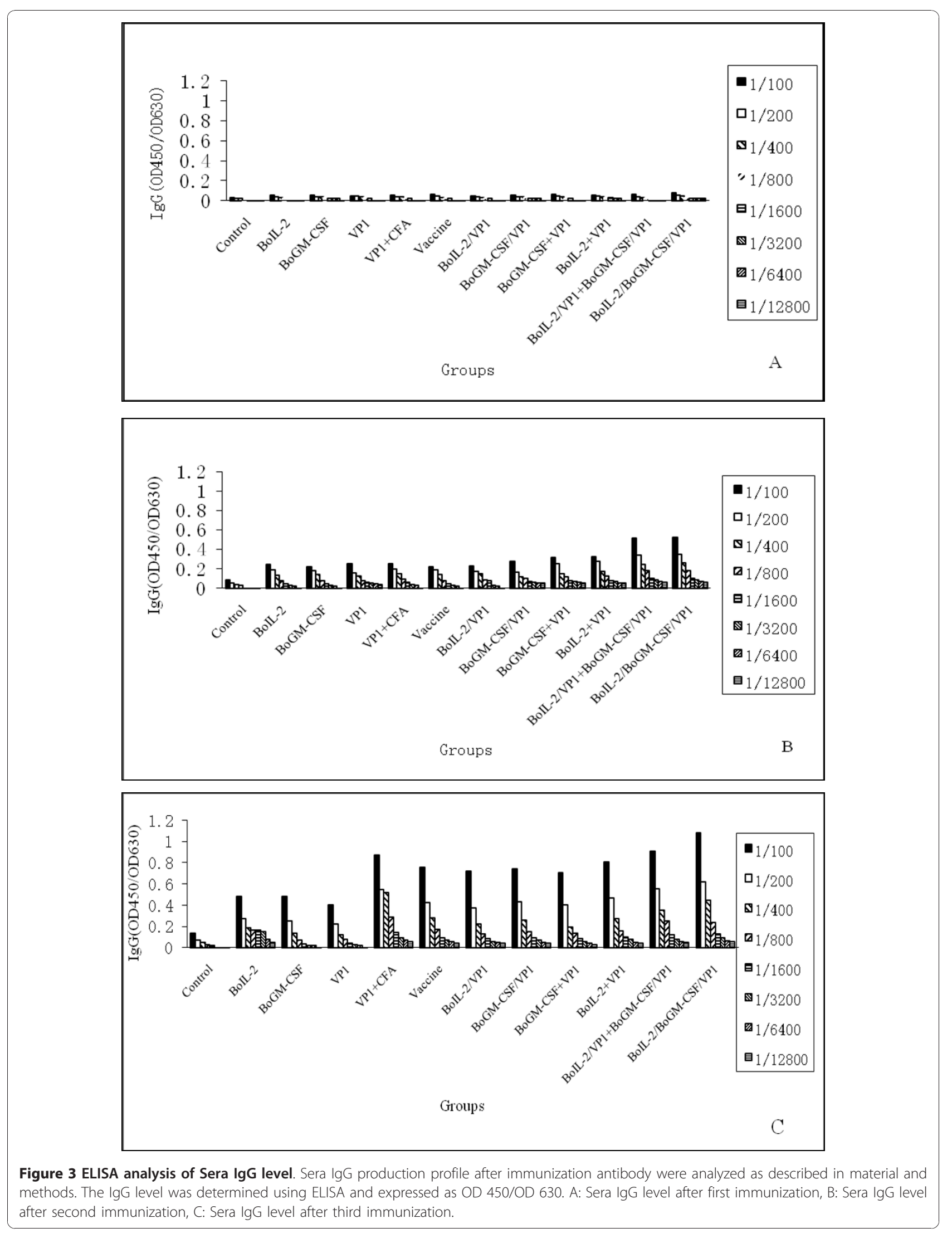


in VP1+CFA group, and groups of single cytokine co-expressed or mixed with VP1 and group of vaccine only induced slightly lower level of IgG than VP1+CFA group, but not significantly different. The control groups immunized with BoIL-2 or BoGM-CSF alone induced the lowest level of IgG compared with PBS control group.

\section{Antigen specific $\mathrm{T}$ lymphocyte proliferation assays}

To determine which cytokine induced better $\mathrm{T}$ cell responses, single suspensions of lymphocytes were prepared from guinea pig after the third immunization and assayed with MTT method. As shown in Figure $4 \mathrm{com}-$ pared with the PBS control group, stimulation indexes (SI) of all groups were increased significantly $(\mathrm{P}<0.05)$. Highest level of proliferation was observed in the group inoculated with BoIL-2/BoGM-CSF/VP1 and followed by the group of BoIL-2/VP1+BoGM-CSF/VP1. The next level of proliferations were observed in four groups given with single cytokine co-expressed or mixed with VP1, followed by VP1 and vaccine groups, but there was no statistically significance with the above four groups.

The result indicated that VP1 plus BoIL-2 and BoGMCSF could induce significant $\mathrm{T}$ cell response, and the combined use of two cytokines had better effect than that of single cytokine as adjuvant. It suggested that these cytokines enhanced the cell-mediated immunity, which was consistent with their known biological function.
Antigen specific delayed-type hypersensitivity response Delayed-type hypersensitivity (DTH) is a memory immune response and directly reflects the cellular immune response of body. All guinea pigs were treated as described before, and then the thicknesses of footpad were measured respectively at $24 \mathrm{~h}, 48 \mathrm{~h}$ and $72 \mathrm{~h}$. The effects of DTH were assessed by the thickness of left footpad and right footpad ratio. As shown in Figure 5 the highest level of DTH was observed in the group of BoIL-2/BoGM-CSF/VP1, followed by groups of $\mathrm{VP} 1+\mathrm{CFA}$ and BoIL-2/VP1+BoGM-CSF/ VP1. The middle level of DTH was seen in the groups of vaccine and VP1, while the DTH level of the four groups that the single cytokine co-expressed or mixed with VP1 were slight lower than the former two groups but no statistically significance. The background level of DTH was from groups of BoIL-2 and BoGM-CSF.

\section{Th1 and Th2 cytokine profile detected}

by semi-quantitative RT-PCR

Cytokines play a dominant role in modulating immune response against infection or in the effectiveness of vaccination. Therefore, semi-quantitative RT-PCR was used to monitor the expression of the representative cytokines. hypoxanthine phosphoribosyl transferase (HPRT), a house-keeping gene, was used as a normalizing control after guinea pigs were immunized. As shown in Figure 6 and Figure 7 the mRNAs of Th1 and Th2 types of

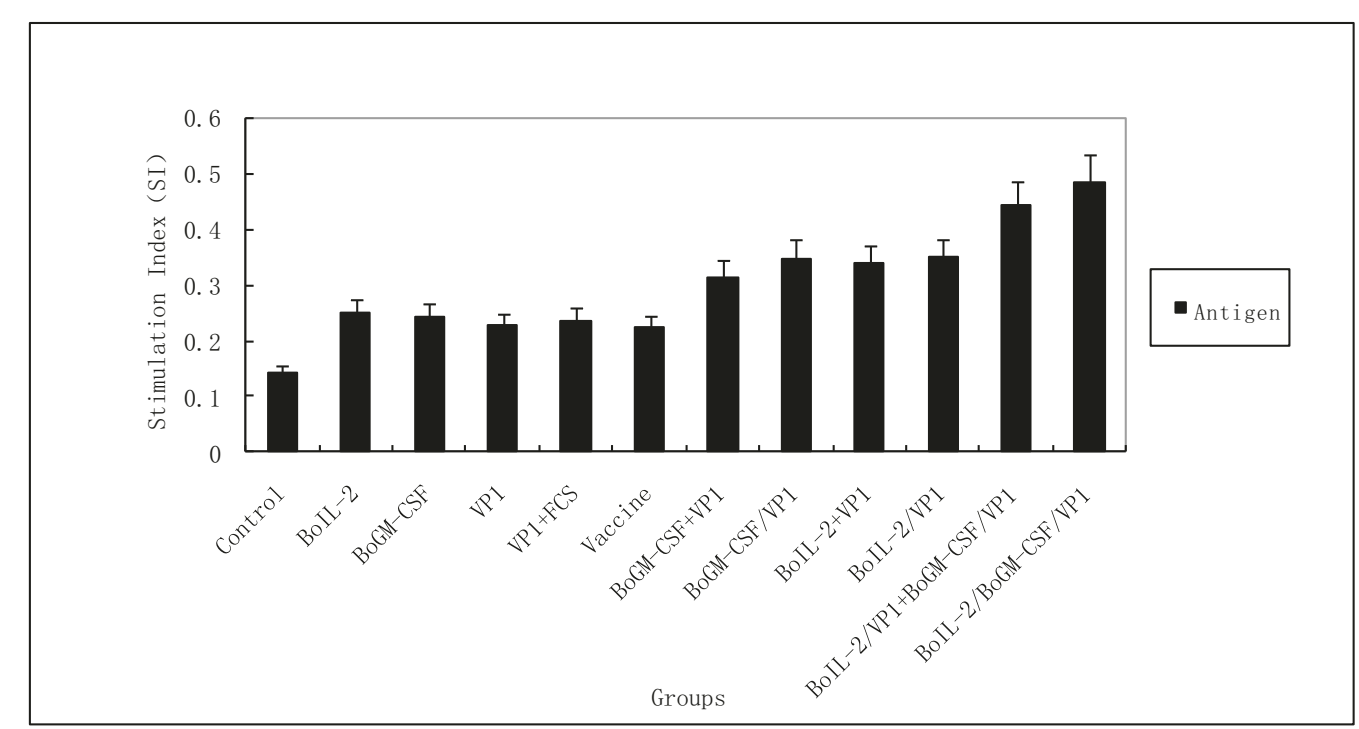

Figure 4 LAP analysis of T lymphocyte stimulation level. T lymphocyte proliferation in response to the inoculations with different proteins. T lymphocytes were isolated from the Guinea pig $(\mathrm{N}=7)$ and stimulated with $146 \mathrm{~S}$ antigen or unstimulated in vitro, and the stimulation index was defined as the ratio of stimulated wells to unstimulated ones. T cell proliferation responses varied among all the groups. 


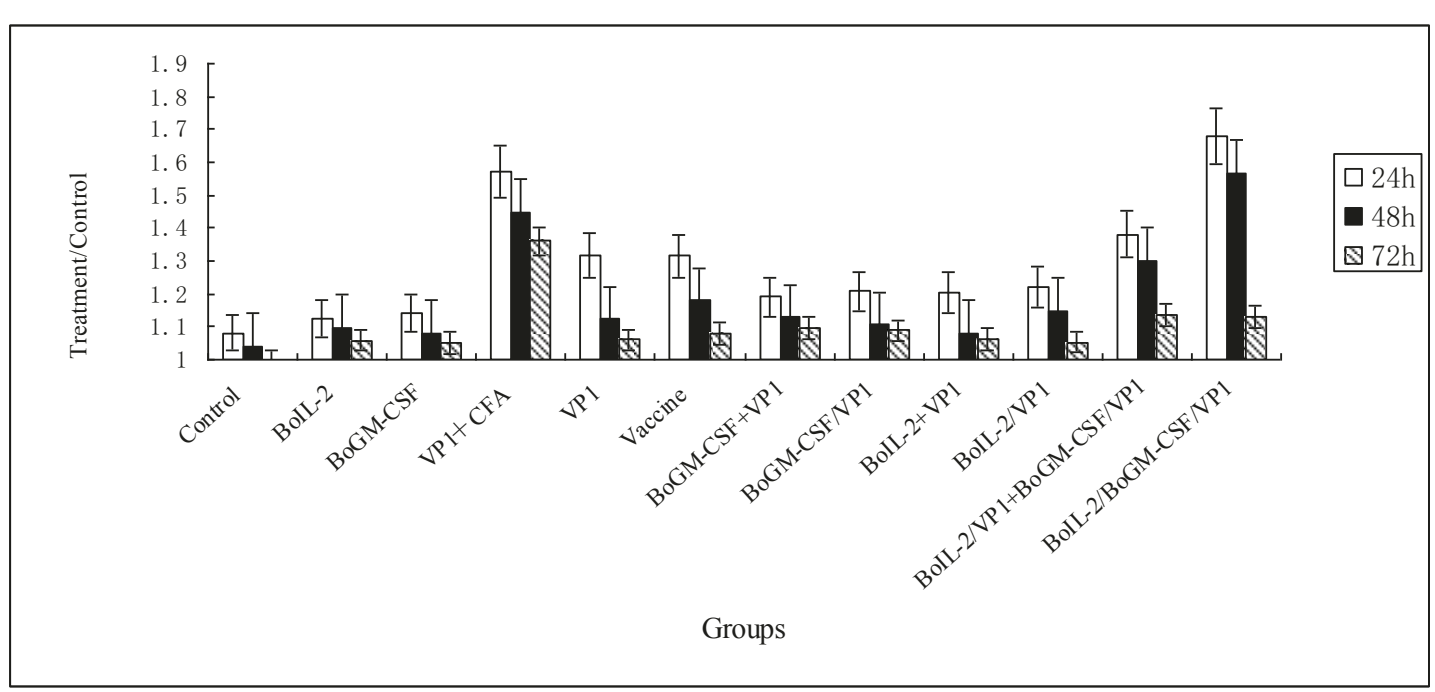

Figure 5 DTH of Guinea pig inoculated with different proteins. Fourteen days after the last inoculation, all Guinea pigs ( $N=7$ ) were challenged counter-laterally with the $146 \mathrm{~S}$ antigen on right footpads as test and saline on left footpads as the negative control. The DTH was defined as the thickness ratio of the right footpad to the left footpad at $24 \mathrm{~h}, 36 \mathrm{~h}$ and $48 \mathrm{~h}$ after the challenges.

cytokines were both evaluated compared with the salineinoculated group. The groups of BoIL-2/BoGM-CSF/ VP1 and BoIL-2/VP1+BoGM-CSF/VP1 showed the highest level of mRNAs of either Th1 or Th2 cytokines. Expression of the cytokines in the groups with single cytokine co-expressed or mixed with VP1 showed the same level of either Th1 or Th2 cytokines as that of groups of Vaccine and VP1. The results indicated that

\section{$\begin{array}{lllllllllllll}1 & 2 & 3 & 4 & 5 & 6 & 7 & 8 & 9 & 10 & 11 & 12\end{array}$}

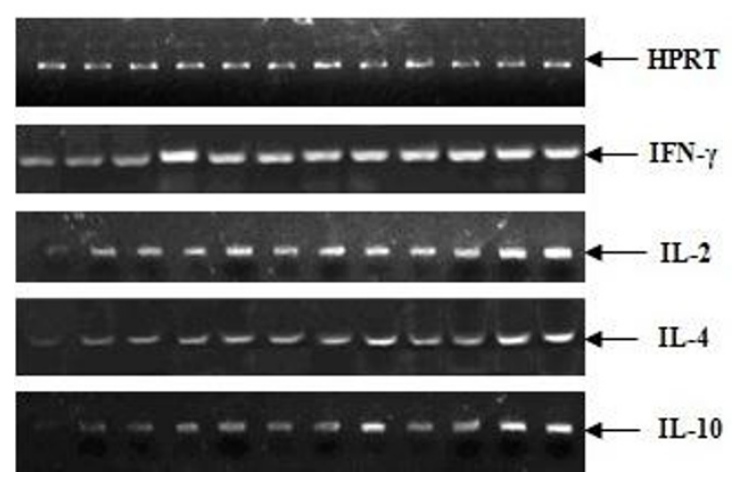

Figure 6 Semi-quantitative RT-PCR of cytokine gene. The levels of the Th1 or Th2 cytokines were quantitatively measured by semiquantitative RT-PCR and showed in Figure 6. For Th1 or Th2 cytokine, mRNA levels were the highest inoculated with the last four groups, followed by co-inoculation with signal cytokine and VP1, VP1 and VP1 + CFA group had the same level with former groups. (1: control, 2: BolL-2, 3: BoGM-CSF, 4: BolL-2NP1, 5: BoGMCSFNP1, 6: VP1, 7: vaccine, 8: VP1+CFA, 9: IL-2+VP1, 10: GM-CSF +VP1, 11: BolL-2/GM-CSFNP1, 12: BolL-2NP1+GM-CSFNP1).
BoIL-2 or BoGM-CSF co-immunized with VP1 could induce both Th1 and Th2 immunity. For the side effects of CFA, group of VP1+CFA showed a higher level of mRNAs of Th2 cytokines than other groups except groups of BoIL-2/BoGM-CSF/VP1 and BoIL-2/VP1 +BoGM-CSF/VP1. Groups of BoIL-2 and BoGM-CSF induced the lowest level of cytokines expression.

\section{Discussion}

As an effective cell activator, complete freund's adjuvant could induce humoral immunity and cellular immunity but were restricted to use by serious side effect. In this regard, we examined the effects of cytokine as adjuvant on promoting cellular or humoral immune response. In this study, IL-2 and GM-CSF were selected as adjuvant since they are well-known to induce immune response $[12,14]$ and examined their effects on VP1 subunit vaccination. As a main immunogenic capsid protein of FMDV, VP1 was successfully expressed and coexpressed with two cytokines respectively in E.coli BL21 for the subsequent immunizations (Table 1). The result of this study indicated that VP1 alone could induce both humoral and cell-mediated immune response as previously observed $[8,9]$.

In our report, the adjuvant activity of GM-CSF and IL-2 was analyzed. Compared with the VP1 group, groups of GM-CSF/VP1, GM-CSF+VP1, IL-2/VP1 and IL-2+VP1 could induce a much higher IgG level and induce a significant $\mathrm{T}$ cell proliferation. It indicated that GM-CSF and IL-2, as adjuvant, could induce both humoral and cell-mediated immune response as for 


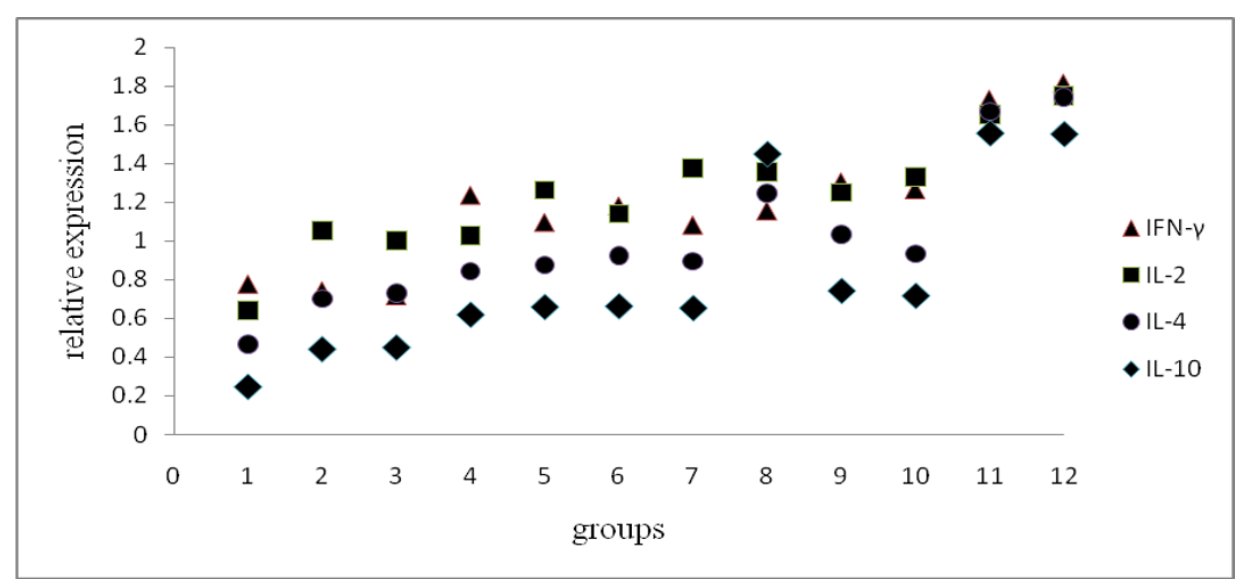

Figure 7 Cytokine gene relative expression analysis of Semi-quantitative RT-PCR. Density of electrophoretic bands in Figure 6 were analysed by band leader 3.0. Taking the data of HPRT bands as the background, Th1 and Th2 cytokine relative expression were evaluated by comparing the intensities of their PCR products and showed in Figure 7. For Th1 or Th2 cytokine, mRNA levels were the highest inoculated with the last four groups, followed by co-inoculation with signal cytokine and VP1, VP1 and VP1 + CFA group had the same level with former groups. (1: control, 2: BolL-2, 3: BoGM-CSF, 4: BolL-2NP1, 5: BoGM-CSFNP1, 6: VP1, 7: vaccine, 8: VP1+CFA, 9: IL-2+VP1, 10: GM-CSF+VP1, 11: BolL-2/GMCSFNP1, 12: BolL-2NP1+GM-CSFNP1).

CFA, suggesting that GM-CSF and IL-2 may become the new potent adjuvant, which was consistent with previously documented [18-21]. Interestingly, the results of ELISA and T cell proliferation showed that IL-2 and GM-CSF, combined or mixed with VP1 as adjuvant, induced a similar immune response level, which indicated that IL-2 and GM-CSF co-expressed or coinoculated with VP1 did not impact their function as adjuvant, which was inconsistent with the results by Shi et al [9].

Cytokines interaction formed regulating network in immune system. In this report, several approaches were used to investigate the combined immune modulating

Table 1 Experiment of groups with different treatment in guinea pigs

\begin{tabular}{ll}
\hline Groups & Treatments \\
\hline Control & PBS \\
1 & BolL-2 \\
2 & BoGM-CSF \\
3 & VP1 \\
4 & inactivated FMDV vaccine \\
5 & VP emulsed in the complete fraued's adjuvant (CFA) VP1+ \\
6 & CFA) \\
7 & Mixture of VP and BolL-2 (VP1+ BolL-2) \\
8 & Mixture of VP1 and BoGM-CSF (VP1+ BoGM-CSF) \\
9 & Co-expressed product of BoGM-CSFNP1 \\
10 & Co-expressed product of BolL-2/BoGM-CSFNP1 \\
11 & Mixture of BolL-2/NP ${ }_{1}$ and BoGM-CSFNP1 (BolL-2NP1+BoGM- \\
& CSFNP1) \\
\hline
\end{tabular}

effects of IL-2 and GM-CSF as adjuvant on FMDV vaccination. All results showed that combined use of IL-2 and GM-CSF with VP1 had a better adjuvant effect than single cytokine. It indicated there was synergistic effect between IL-2 and GM-CSF, which was consistent with the previous reports $[15,22,23]$ This may be due to that GM-CSF could attract APC and enhanced the antigen presentation when the VP1 was injected with IL-2 and GM-CSF [24]; IL-2 receptor expression was elevated for the interaction between TCR and antigen [25]. Furthermore, IL-2 could directly enhanced IL-2 receptor expression on antigen selected T cells [26] and could further stimulate the growth and differentiation of those $\mathrm{T}$ cells. Interestingly, the adjuvant effect was observed in the BoIL-2/BoGM-CSF/VP1 group rather than in the BoIL-2/VP1+BoGM-CSF/VP1 group, suggesting that IL-2 and GM-CSF co-expressed as adjuvant had a better synergistic effect than co-inoculated with VP1. This probably because, in addition to the suggested synergies, the two fusion cytokines may also had "bridge" function, which could combine surface receptors of $\mathrm{T}$ cells, macrophages and DC cell respectively, then formed IL2/GM-CSF "bridge" in T cells, macrophages and DC cell. This "bridge" could increase the contact of DC and $\mathrm{T}$ cell in a short time and the binding of receptor and ligand, therefore, enhancing the antigen-presenting ability of APC, subsequently enhancing the level of cell and humoral immune response, leading to a better adjuvant function than single cytokine. Further experiments are needed to test our hypothetic explanation.

DTH reflected the cell-mediated immune function and especially the manifestation of Th1 type of effect cells. 
As expected, DTH result was consistent with the results of ELISA and $\mathrm{T}$ cell proliferation. It was worth noting that the DTH response level of VP1+CFA group was higher than groups of single cytokine co-expressed or mixed with VP1. The reason for this could be nonspecific stimulation of CFA.

In semi-quantitative RT-PCR, the mRNA levels for IFN- $\gamma$, IL-2, IL-4 and IL-10 were measured to assess the profile of cytokines after immunization. Th1 and Th2 type cytokines were all increased after the co-inoculation with recombined proteins in this study, which indicated IL-2 and GM-CSF up-regulated, sequentially, both Th1 and Th2 responses. Groups of BoIL-2/BoGM-CSF/VP1 and BoIL-2/VP1+BoGM-CSF/VP1 could induce the highest expression level of either Th1 or Th2 type cytokines, followed by other groups, which were consistent with the results of ELISA, T lymphocyte proliferation response and DTH. CFA, as the most widely used adjuvant in practical vaccination at present, induced a Th2 subset, which was also reported in other studies [27].

In this report we investigated the ability of IL-2 and GM-CSF as adjuvant to modulate host immune response against FMDV in the controlled experimental conditions. IL-2 or GM-CSF could stimulate cellular and humoral immune response, was a potential adjuvant for the FMDV vaccination. We, for the first time, showed that IL-2 or GM-CSF co-expressed or co-inoculated with VP1 had the equal effect as adjuvant; Two cytokines, GM-CSF and IL-2, when co-expressed with VP1 had a better synergistic effect than that of the coinoculated. Further evaluation on efficacies and optimizing the immunization pigs and cattle will be the next in our study.

\section{Conclusions}

In summary, the current study indicated the potential for the use of IL-2 and GM-CSF as alternative adjuvant for FMDV vaccination. The study also showed that there was synergistic effect when GM-CSF and IL-2 coexpressed with VP1, which will be useful for further research on FMD vaccines.

\section{Materials and methods}

Reagents and antigens

RNA isolation and reverse transcription reagent Kits were purchased from Promega (Madison, Wisc., USA), ExTag DNA polymerase and all restriction enzymes were purchased from TaKaRa (Dalian, China), BL21 expression vector, pGEX-6p-1, was purchased from Invitrogene, horseradish peroxidase(HRP)-conjugated goat anti-mouse IgG, MTT and TMB were from Sigma (St. Louis, USA). Eight-week-old female guinea pigs were purchased from the Institute of Genetics of Chinese Academy of Sciences.
FMDV O-serotype inactivated vaccine in oil emulsion was acquired from Zhongmu Ltd. (Beijing, China), and the $146 \mathrm{~S}$ antigen component was obtained from the purified as described previously and stored at $4^{\circ} \mathrm{C}$. The concentration of the $146 \mathrm{~s}$ antigen was determined by the Bradford protocol as described previously [28]. $146 \mathrm{~S}$ particle contains four major discrete proteins, VP1, VP2, VP3 and VP4. VP1 is the dominant one and provides the major neutralising and $\mathrm{T}$ cell epitopes among these four proteins. Therefore, $146 \mathrm{~S}$ provides complete antigens/ epitopes for the ELISA and $\mathrm{T}$ cell proliferation assays.

Cloning, expression and co-expression of targeted genes After isolation of peripheral blood mononuclear cells (PBMC) from Holstein cow and stimulated with Con A $(10 \mu \mathrm{g} / \mathrm{mg})$ for $2 \mathrm{~h}$ in vitro, total RNA was extracted and reverse transcribed into cDNA by using RNA isolation kit and reverse transcription reagent kit(Promega Inc.) according to the manufacturer's instructions.

The VP1 fragment was amplified from the plasmid PMD18-VP1 (gift from Jin Huali, China Agricultural University). The active mature peptide of BoIL-2 and BoGM-CSF were amplified from CDNA. PCR conditions and primers were indicated as Table 2. The PCR products of BoIL-2, BoGM-CSF and VP1 were purified and digested. All the digested fragments were inserted into the pGEX-6p-1 plasmid respectively, designated as pGEX/BoIL-2, pGEX/GM-CSF and pGEX/VP1.

For the co-expression of BoIL-2 and VP1 in E. coli, the VP1 fragment was amplified from the plasmid PMD18-VP1 with the upstream primer VP1 F1 and downstream primer VP1 R1 and digested with EcoRI and XhoI. The IL-2 fragment was subcloned from plasmids pGEX/BoIL-2 and digested with BamHI and EcoRI. The expression vector pGEX-6p-1 was also digested with BamHI and XhoI. All the digested fragments were ligated by $\mathrm{T}_{4}$ DNA ligase to yield three constructs, designated as pGEX/BoIL-2/VP1. Between fragments of BoIL-2 and VP1, they were divided by five glycine residues as linker.

For the co-expression of VP1 and BoIL-2, BoGM-CSF in E. coli, IL-2, GM-CSF and VP1 were subcloned from plasmids pGEX/BoIL-2, pGEX/GM-CSF and pGEX/ VP1. The PCR products of BoIL-2, BoGM-CSF and VP1 were purified and digested respectively. The expression vector pGEX-6p-1 was also digested with BamHI and XhoI. All the digested fragments were ligated by $\mathrm{T}_{4}$ DNA ligase respectively, designated as pGEX/IL-2/VP1, pGEX/GM-CSF/VP1, pGEX/BoIL-2/BoGM-CSF/VP1. Between fragments of BoIL-2 and VP1, BoIL-2 and BoGM-CSF, or BoGM-CSF and VP1, they were joined by five glycine residues as linkers.

These constructs were transformed into E. coli BL21 in LB plate with $50 \mu \mathrm{g} / \mathrm{ml}$ of Amp+ selection, followed 
Table 2 Primers for cloning PCR

\begin{tabular}{|c|c|c|c|c|}
\hline Target genes* & Primer code & Primers Sequences $\left(5^{\prime}-3^{\prime}\right)^{* *}$ & Fragment length & PCR condition \\
\hline \multirow[t]{2}{*}{ BolL-2 } & Boll-2 F & $\begin{array}{l}\text { 5' GAA GGA TCC CAC CTC CTA CTT CAA } \\
\text { GCT CTA CG } 3^{\prime}\end{array}$ & $405 \mathrm{bp}$ & $\begin{array}{c}94^{\circ} \mathrm{C} \text { for } 60 \mathrm{~s}, 62^{\circ} \mathrm{C} \text { for } 60 \mathrm{~s} \text { and } 72^{\circ} \mathrm{C} \text { for } \\
60 \mathrm{~s}, 35 \text { cycles }\end{array}$ \\
\hline & Boll-2 R & $\begin{array}{l}\text { 5' CTA GAA TTC CAA GTC ATT GTT GAG } \\
\text { TAG ATG C } 3^{\prime}\end{array}$ & & \\
\hline \multirow[t]{2}{*}{ BoGM-CSF } & BoGM-CSF F & $\begin{array}{l}\text { 5' CTA GAA TTC GCA CCT ACT CGC CCA } \\
\text { CCC AA } 3^{\prime}\end{array}$ & $378 \mathrm{bp}$ & $\begin{array}{c}94^{\circ} \mathrm{C} \text { for } 60 \mathrm{~s}, 62^{\circ} \mathrm{C} \text { for } 60 \mathrm{~s} \text { and } 72^{\circ} \mathrm{C} \text { for } \\
60 \mathrm{~s}, 35 \text { cycles }\end{array}$ \\
\hline & BoGM-CSF R & $\begin{array}{l}5^{\prime} T T A C C G \text { CGG } C T T \text { CTG GGC TGG TTC } \\
\text { CCA G } 3^{\prime}\end{array}$ & & \\
\hline \multirow[t]{4}{*}{ VP1 } & VP1 F & $\begin{array}{l}\text { 5'GCA CCG CGG ACC ACC TCT GCG GGT } \\
\text { GAG TCT 3' }\end{array}$ & $669 \mathrm{bp}$ & $\begin{array}{c}94^{\circ} \mathrm{C} \text { for } 60 \mathrm{~s}, 61^{\circ} \mathrm{C} \text { for } 60 \mathrm{~s} \text { and } 72^{\circ} \mathrm{C} \text { for } \\
60 \mathrm{~s}, 35 \text { cycles }\end{array}$ \\
\hline & VP1 R & $\begin{array}{l}5^{\prime} G A C \text { CTC GAG CAG AAG CTG TTा TGC } \\
\text { GGG T } \frac{3^{\prime}}{}\end{array}$ & & \\
\hline & VP1 F1 & $\begin{array}{l}\text { 5'GCA GAA TTC ACC ACC TCT GCG GGT } \\
\text { GAG TCT } 3^{\prime}\end{array}$ & & \\
\hline & VP1 R1 & $\begin{array}{l}5^{\prime} G A C \frac{C T C}{C A G} \text { CAG AAG CTG TाT TGC } \\
\text { GGG T } \frac{3^{\prime}}{}\end{array}$ & & \\
\hline
\end{tabular}

by the identification procedures using both restriction enzyme digestions and PCR. The further confirmation was performed by sequencing analysis.

The confirmed colonies were cultured into LB liquid medium with $50 \mu \mathrm{g} / \mathrm{ml}$ of $\mathrm{Amp}+$ at $37^{\circ} \mathrm{C}$ until the $\mathrm{OD}_{600}$ value reached 0.5 . The expression was induced for $6 \mathrm{~h}$ with addition of IPTG to achieve a final concentration of $1 \mathrm{mM}$.

\section{Characterizations of expressed proteins by SDS-PAGE and Western blot analysis}

Sample of $100 \mu$ l cultures from each recombinant E. coli were homogenized by ultrasonic treatment at $0^{\circ} \mathrm{C}$. The protein samples in supernatant and precipitation were subjected in a $15 \%$ SDS-PAGE.

The inclusion bodies after ultrasonic treatment were washed three times in $10 \mathrm{mmol} / \mathrm{L}$ Tris-Cl buffer (10 mmol/L EDTA, 0.5\% Tritonx-100, $0.2 \mathrm{~mol} / \mathrm{L}$ Urea $\mathrm{pH}=8.0$ )and subsequently washed three times in 10 $\mathrm{mmol} / \mathrm{L}$ Tris-Cl buffer $(10 \mathrm{mmol} / \mathrm{L}$ EDTA, $0.5 \%$ Tritonx-100, $\mathrm{pH}=8.0)$. Then the inclusion bodies were stepwise dialysed $6 \mathrm{~h}$ with Tris-Cl buffer $(8 \mathrm{~mol} / \mathrm{L}$ Urea, $6 \mathrm{~mol} / \mathrm{L}$ Urea, $4 \mathrm{~mol} / \mathrm{L}$ Urea and $2 \mathrm{~mol} / \mathrm{L}$ Urea in each Tris-Cl buffer) and PBS. Purified proteins were collected for Western blot analysis and subsequent immunization.

Purified protein samples were transferred onto the nitrocellulose membrane. The membrane was incubated overnight in $5 \%$ bovine serum albumin in Tris-buffered saline-Tween 20 at $4^{\circ} \mathrm{C}$ before washing for three times in TBS. Subsequently, the membrane was incubated at $37^{\circ} \mathrm{C}$ for $2 \mathrm{~h}$ with the sera of guinea pig anti- BoIL-2, guinea pig anti-BoGM-CSF and bovine FMDV positive sera, diluted 1:1000 in blocking solution. The membrane was washed in TBS and then incubated at $37^{\circ} \mathrm{C}$ for $2 \mathrm{~h}$ with HRP-labeled goat anti-mouse IgG(Sigma), diluted
1:500 in blocking solution. The membrane was washed again and the signals were developed with DAB substrate.

\section{Immunization and detection of FMDV antibody}

Eighty four female guinea pigs were randomly divided into twelve groups ( $\mathrm{N}=7$ per group) as Table 1 and were 2 -weeks old at the time of the first immunization. Protein products were injected at the equal total dosage $(500 \mu \mathrm{g}$ per guinea pig, in PBS) by hypodermic multisite injections respectively. Negative control group was injected PBS (100 $\mu \mathrm{l}$ per guinea pig) with the same volume. All test groups were immunized three times with two weeks interval. Sera were collected before vaccination and on the $14^{\text {th }}$ day post each immunization and subsequently analyzed for detection of FMDV antibody.

ELISA plates were used to detect anti-FMDV antibodies in guinea pigs as described previously [8,18]. $146 \mathrm{~S}$ antigens $(2 \mu \mathrm{g} / \mathrm{ml})$ were coated on ELISA plates at $4^{\circ} \mathrm{C}$ overnight and subsequently reacted with sera diluted at 1:100 for $1 \mathrm{~h}$ at $37^{\circ} \mathrm{C}$. Then sera reacted with $1: 1000$ diluted goat anti-guinea pigs IgG conjugated with HRP. To detect the ELISA result, colorimetric reaction was developed with TMB (Sigma) and stopped by $\mathrm{H}_{2} \mathrm{SO}_{4}$ and the OD reading was determined at $450 \mathrm{~nm} / 655 \mathrm{~nm}$ with a plate reader (Bio-Rad, CA, USA).

\section{T lymohocyte proliferation}

Guinea pigs were immunized as described earlier. Two weeks after final immunization, Guinea pigs were sacrificed and spleens were removed aseptically. Spleen cells were plated at $5 \times 10^{4}$ cells per well and cultured in triplicate wells for $48 \mathrm{~h}$ in presence of $10 \mu \mathrm{g} / \mathrm{ml}$ of $146 \mathrm{~s}$ antigen or alone. Culture supernatants were tested to quantify the $\mathrm{T}$ cell proliferation as described previously 
[18]. T lymphocyte proliferation was expressed as stimulation index $(\mathrm{SI})$, which is the ratio of $\mathrm{OD}_{570 \mathrm{~nm}}$ of stimulated well (stimulated cell) to $\mathrm{OD}_{570 \mathrm{~nm}}$ of unstimulated one [18].

\section{Antigen specific delayed-type Hypersensitivity (DTH)}

Two weeks after the last immunization, Guinea pigs were injected with the $146 \mathrm{~S}$ antigen into the right footpads and saline into the left as the negative control. Then the thicknesses of footpads were measured respectively at $24 \mathrm{~h}, 48 \mathrm{~h}$ and $72 \mathrm{~h}$ with micrometer to assess the effects of DTH $[8,18]$.

\section{Semi-quantitative RT-PCR for mRNA of cytokines}

Guinea pigs were immunized as described earlier. Two weeks after final immunization, Guinea pigs were sacrificed and spleens were removed aseptically. The lymphocytes were separated from spleens and plated in the 6-well microtiter plate at $5 \times 10^{4}$ cells per well. The lymphocytes were cultured in triplicate wells with antigen stimulations for $1 \mathrm{~h}$ in RPMI-1640 containing 10\% FCS. The total RNA was extracted from those cells and the cDNA was synthesized as described above. PCR conditions were optimized with specific primers for the housekeeping gene (HPRT) or cytokine genes indicated as Table 3.

PCR parameters were performed with minor modifications. Briefly, the PCR mixtures contained $5 \mu \mathrm{l}$ of PCR buffers, $4 \mu \mathrm{l}$ of dNTP, $0.5 \mu \mathrm{l}$ of ExTaq polymerase, $2 \mu \mathrm{g}$ of cDNAs and $0.5 \mu \mathrm{l}$ of each primer. The PCR was performed for 32 cycles with parameters of denaturation at $94^{\circ} \mathrm{C}$ for $1 \mathrm{~min}$, annealing at $60^{\circ} \mathrm{C}$ for $30 \mathrm{~s}$, extension at $72^{\circ} \mathrm{C}$ for $1 \mathrm{~min}$, and a final extension at $72^{\circ} \mathrm{C}$ for 10 min. cDNA from each group was first normalized with

Table 3 Primers for Semi-quantitative RT-PCR

\begin{tabular}{|c|c|c|c|}
\hline $\begin{array}{l}\text { Target } \\
\text { genes }\end{array}$ & primers & $\begin{array}{l}\text { Fragment } \\
\text { length }\end{array}$ & References \\
\hline HPRT & $\begin{array}{l}5^{\prime} \text { GTT GGA TAC AGG CCA GAC } \\
\text { TIT GTT G } \\
3 \text { GAG GGT AGG CTG GCC TAT } \\
\text { GGC T }\end{array}$ & $352 \mathrm{bp}$ & [28] \\
\hline IL-2 & $\begin{array}{l}5^{\prime} \text { TCC ACT TGA AGC TCT } \\
\text { ACA G } \\
\text { 3' GAG TGA AAT CCA GAA } \\
\text { CAT GCC }\end{array}$ & $247 \mathrm{bp}$ & \\
\hline $\mathrm{IFN}-\gamma$ & $\begin{array}{l}\text { 5' CAT TGA AAG CCT AGA } \\
\text { AAG TCT G } \\
\text { 3' CTC ATG GAA ATG CAT CCT } \\
\text { TाT TCG }\end{array}$ & $267 \mathrm{bp}$ & \\
\hline IL-4 & $\begin{array}{l}\text { 5' GAA AGA GAC CTT GAC ACA } \\
\text { GCT G } \\
\text { 3' GAA CTC TTG CAG GTA ATC } \\
\text { CAG G }\end{array}$ & $240 \mathrm{bp}$ & \\
\hline IL-10 & $\begin{array}{l}\text { 5' CCA GTT TTA CCT GGT AGA } \\
\text { AGT GAT G } \\
\text { 3' TCT GGT CCT GGA GTC CAG } \\
\text { CAG ACT CAA }\end{array}$ & $324 \mathrm{bp}$ & \\
\hline
\end{tabular}

the house-keeping gene, HPRT as a reference, each adjusted cDNA was used as template to amplify IFN- $\gamma$, IL-2, and IL-4, respectively, according to the conditions described above. All these PCR products were subjected onto electrophoresis on $1.5 \%$ of agarose gel and photographed under the UV light [18]. Density of electrophoretic bands in agarose gel were analysed by band leader 3.0. Taking the data of HPRT bands as the background, the relative amount of mRNAs for the cytokinespecific genes was evaluated by comparing the intensities of their PCR products.

\section{Statistical analysis}

Statistical significance between the treatment groups was calculated using One-sided Student's $t$-test and $\mathrm{P}<0.05$ was considered statistically significant.

\section{Acknowledgements}

This work was supported by the National High Technology Research and Development Program (No. 2001AA249032) and the National "10.5" Key Technologies R\&D Program (No. 2002BA514A-16-4).

\section{Author details}

${ }^{1}$ College of Veterinary Medicine, China Agricultural University, Beijing 100193, China. ${ }^{2}$ State Key Lab of Agro-Biotechnology and College of Biological Sciences, China Agricultural University, Beijing 100193, China. ${ }^{3}$ College of Veterinary Science, Qingdao Agricultural University, Qingdao 266109, China.

\section{Authors' contributions}

CZ carried out the experiments and wrote the manuscript. BW participated in experimental design and paper revise. MW conceived the studies and participated in experimental design and coordination. All authors read and approved the final manuscript.

\section{Competing interests}

The authors declare that they have no competing interests.

Received: 23 August 2010 Accepted: 9 January 2011

Published: 9 January 2011

\section{References}

1. Audibert FM, Lise LD: Adjuvants: current status, clinical perspectives and future prospects. Immunology Today 1993, 14:281-284.

2. Vogel FR: Adjuvants in perspective. Dev Biol Stand 1998, 92:241-248.

3. Gupta RK, Rost BE, Relyveld E, Siber GR: Adjuvant properties of aluminium and calcium compounds. Pharm Biotechnol 1995, 6:229-248.

4. Gupta RK: Aluminum compounds as vaccine adjuvants. Adv Drug Deliv Rev 1998, 32(3):155-1725.

5. el Kassas H, Kirkwood JM: Adjuvant application of interferons. Semin Oncol 1996, 23(6):737-743.

6. Singh M, O'Hagan D: Advances in vaccine adjuvant. Nat Biltechnol 1999, 17(11):1075-1081.

7. Scheerlinck JY: Genetic adjuvants for DNA vaccines. Vaccine 2001, 19:2647-2656.

8. Shi XJ, Wang B, Zhang C, Han CL, Wang M: Expressions of Bovine IFN- $\gamma$ and Foot-and-Mouth Disease VP1 antigen in P. pastoris and their effects on mouse immune response to FMD antigens. Vaccine 2006, 24(1):82-89.

9. Shi XJ, Wang B, Wang M: Immune enhancing effects of recombinant bovine IL-18 on foot-and-mouth disease vaccination in mice model. Vaccine 2007, 25:1257-1264

10. Wang $X$, Zhang XY, Kang YM, Jin HL, Du XG, Zhao G, Yu Y, Li JY, Su BW, Huang C, Wang B: Interleukin-15 enhance DNA vaccine elicited mucosal and systemic immunity against foot and mouth disease virus. Vaccine 2008, 26(40):5135-5144. 
11. Su B, Wang J, Wang X, Jin H, Zhao G, Ding Z, Kang Y, Wang B: The effects of IL-6 and TNF-alpha as molecular adjuvants on immune responses to FMDV and maturation of dendritic cells by DNA vaccination. Vaccine 2008, 26(40):5111-5122.

12. Caligiuri MA, Murray C, Robertson MJ, Wang E, Cochran K, Cameron C, Schow P, Ross ME, Klumpp TR, Soiffer RJ: Selective modulation of human natural killer cell in vivo after prolonged infusion of low-dose recombinant interleukin-2. J Clin Invest 1993, 91(1):123-132.

13. Romagnani S: Th1/Th2 cells. Inflamm Bowel Dis 1999, 5(4):285-294.

14. Disis ML, Bernhard H, Shiota FM, Hand SL, Gralow JR, Huseby ES, Gillis S, Cheever MA: Granulocyte-macrophage colony-stimulating factor: An effective adjuvant for protein and peptide-based vaccines. Blood 1996, 88(1):202-210.

15. Toubaji A, Hill S, Terabe M, Qian J, Floyd T, Simpson RM, Berzofsky JA, Khleif SN: The combination of GM-CSF and IL-2 as local adjuvant shows synergy in enhancing peptide vaccines and provides long term tumor protection. Vaccine 2007, 25(31):5882-91.

16. Yoon HA, Aleyas AG, George JA, Park SO, Han YW, Lee JH, Cho JG, Eo SK: Cytokine GM-CSF genetic adjuvant facilitates prophylactic DNA vaccine against pseudorabies virus through enhanced immune responses. Microbiol Immunol 2006, 50(2):83-92.

17. Sun X, Hodge LM, Jones HP, Tabor L, Simecka JW: Co-expression of granulocyte-macrophage colony-stimulating factor with antigen enhances humoral and tumor immunity after DNA vaccination. Vaccine 2002, 20(9-10):1466-1474.

18. Sin Jl, Kim JJ, Ugen KE, Ciccarelli RB, Higgins TJ, Weiner DB: Enhancement of protective humoral (Th2)and cell-medicated (Th1) immune responses against herpes simplex virus-2 through co-delivery of granulocytemacrophage colony-stimulating factor expression cassettes. Eur J Immunol 1998, 28:3530-3540.

19. Hartung $T$, von Aulock $S$, Freitag M, Höxtermann $S$, Stücker M, Hoffmann $K$, Altmeyer P, Kottke A, Wendel A: Blood cytokine response of low-dose molgramostim(rhGM-CSF) -treated patients. Cytokine 2000, 12:1570.

20. Ogawa T, Kusumoto M, Kuroki S, Nagata S, Yamanaka N, Kawano R, Yoshida J, Shinohara M, Matsuo K: Adjuvant GM-CSF cytokine gene therapy for bresat cancer. Gan To Kagaku Ryoho 2001, 28(11):1512-1514.

21. Somasundaram C, Takamatsu H, Andréoni C, Audonnet JC, Fischer L, Lefèvre F, Charley B: Enhanced protective response and immunoadjuvant effects of procine GM-CSF on DNA vsccination of pigs against Aujeszky's disease virus. Vet Immunol Immunopathol 1999, 70(3-4):277-287.

22. Boyaka PN, McGhee JR: Cytokines as adjuvants for the induction of mucosal immunity. Adv Drug Deliv Rev 2001, 51:71-19.

23. Westermann J, Reich G, Kopp J, Haus U, Dörken B, Pezzutto A: Granulocyte/macrophage-colony-stimulating-factor plus interleukin-2 plus interferon alpha in the treatment of metastatic renal cell carcinoma: a pilot study. Cancer Immunol Immunother 2001, 49(11):613-620.

24. Ahlers JD, Belyakov IM, Matsui S, Berzofsky JA: Mechanisms of cytokine synergy essential for vaccine protection against viral challenge. Int Immunol 2001, 13(7):897-908.

25. Cantrell DA, Smith KA: Transient expression of interleukin 2 receptors. Consequences for T cell growth. J Exp Med 1983, 158(6):1895-1911.

26. Depper JM, Leonard WJ, Drogula C, Kronke M, Waldmann TA, Greene WC: Interleukin 2(IL-2) augments transcription of the IL-2 receptor gene. Proc Natl Acad Scin USA 1985, 82(12):4230-4234.

27. Brewer JM, Conacher M, Satoskar A, Bluethmann H, Alexander J: In interleukin-4-deficient mice, alum not only generates T helper 1 responses equivalent to freund's complete adjuvant, but continues to induce T helper 2 cytokine production. Eur I Immunol 1996, 26(9):2062-2066

28. Jin HL, Li YJ, Ma ZH, Zhang FC, Xie QG, Gu DF, Wang B: Effect of chemical adjuvants on DNA vaccination. Vaccine 2004, 29(21 22):2925 2935.

doi:10.1186/1743-422X-8-7

Cite this article as: Zhang et al:: GM-CSF and IL-2 as adjuvant enhance the immune effect of protein vaccine against foot-and-mouth disease. Virology Journal 2011 8:7.

\section{Submit your next manuscript to BioMed Central and take full advantage of:}

- Convenient online submission

- Thorough peer review

- No space constraints or color figure charges

- Immediate publication on acceptance

- Inclusion in PubMed, CAS, Scopus and Google Scholar

- Research which is freely available for redistribution

Submit your manuscript at www.biomedcentral.com/submit 